\title{
Edukasi Game Jaga Sungai Kapuas Berbasis Android Menggunakan Construct 2
}

\author{
Nahel Al Fath Ichida ${ }^{\# 1}$, Helfi Nasution ${ }^{\# 2}$, Anggi Perwitasari ${ }^{\# 3}$ \\ \#Program Studi Informatika Fakultas Teknik Universitas Tanjungpura \\ Jl. Prof Dr H. Hadari Nawawi, Kota Pontianak, 78115 \\ Ialfathichida96@gmail.com \\ ${ }^{2}$ helfi nasutioneyahoo.com \\ ${ }^{3}$ anggiperwitasari@informatikauntan.ac.id
}

\begin{abstract}
Abstrak - Sungai Kapuas di kota Pontianak merupakan sumber kehidupan bagi masyarakat di sepanjang aliran sungai. Selain itu juga sebagai sarana transportasi dan rekreasi dengan Sungai Kapuas telah tercemar oleh berbagai macam limbah dan sampah. CAI (Computer Assisted Instruction) menyampaikan materi pelajaran menggunakan komputer yang pelajarannya dirancang dan diprogram ke dalam sistem. Penelitian ini menghasilkan aplikasi game edukasi Jaga Sungai Kapuas berbasis Android yang mampu menjadi media edukasi dan sosialisasi kebersihan sungai. Hasil yang diperoleh berdasarkan pada pengujian Alpha adalah, aspek Functionality dengan nilai sebesar 77,00\% (layak), aspek Efficiency sebesar 75,00\% (layak), dan Usability sebesar $\mathbf{7 3 , 0 0 \%}$ (layak). Hasil keseluruhan dari tiga aspek yang menjadi fokus pada uji

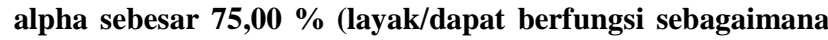
mestinya). Pengujian selanjutnya yaitu pengujian Beta diperoleh hasil untuk aspek Functionality sebesar 93,00\% (sangat layak), aspek Efficiency sebesar 85,00\% (sangat layak), aspek Usability sebesar $\mathbf{8 8 , 0 0 \%}$ (sangat layak), dan aspek Portability sebesar $\mathbf{8 9 , 0 0 \%}$ (sangat layak). Hasil keseluruhan dari empat aspek kualitas perangkat lunak yang menjadi fokus pada uji Beta adalah $89,44 \%$ (sangat layak).
\end{abstract}

Kata kunci - Sungai Kapuas, CAI, Edukasi, Game, Android,

\section{Pendahuluan}

Sungai Kapuas di kota Pontianak merupakan sumber kehidupan bagi masyarakat di sepanjang aliran sungai. Karakteristik sungai Kapuas sebagai ruang lingkup pemukiman menyebabkan masyarakat sering membuang sampah di badan sungai yang mengakibatkan sungai menjadi tercemar. Kondisi air sungai Kapuas saat ini telah tercemar dan tidak memenuhi baku mutu air berdasarkan PP No. 82 Th 2001 [1]. Sampah tersebut sangat mengganggu estetika kawasan tepian sungai.
Tingkat pendidikan yang rendah mempengaruhi perilaku membuang sampah [2]. Masyarakat perlu diberikan pemahaman tentang tata cara pengelolaan sampah yang baik, dan menghasilkan tambahan pendapatan masyarakat.

Game dapat digunakan sebagai media mengedukasi masyarakat mengenai pencemaran sungai. Game dapat dirancang dengan menggunakan sistem yang dinamakan CAI. CAI (Computer Assisted Instruction) menyampaikan materi pelajaran menggunakan komputer yang pelajarannya dirancang dan diprogram ke dalam sistem tersebut.

Construct 2 adalah sebuah game engine berbasis HTML5 yang dapat digunakan untuk membangun game atau aplikasi dengan sistem CAI.

Penelitian ini bertujuan untuk membangun aplikasi berupa game edukasi yang bernama "Jaga Sungai Kapuas". Game ini diharapkan mampu memberikan edukasi tentang jenis-jenis sampah, dampak dan manfaatnya serta lokasi persebaran TPS terdekat.

\section{URAIAN PENELITIAN.}

Penelitian tentang pembuatan game edukasi sebelumnya sudah pernah dilakukan oleh peneliti lain. Pada peneletian sebelumnya game tentang edukasi sudah pernah di buat oleh mahasiswa Universitas Tanjungpura yang menggangkat Game Edukasi Pembelajaran Matematika menggunakan Construct 2, untuk memberikan pelajaran matematika pada anak-anak.[3]

\section{A. Computer Assisted Instruction (CAI)}

Computer Assisted Instruction (CAI) adalah suatu sistem penyampaian materi pelajaran yang berbasis komputer yang pelajarannya dirancang dan diprogram ke dalam sistem tersebut [4]. Komputer bisa menampilkan pembelajaran, menggunakan berbagai jenis media (teks, gambar, suara, video). 


\section{Model Educational Games}

Tipe educational games merupakan program yang menciptakan kemampuan pada lingkungan permainan [5] Permainan diberikan sebagai alat untuk memotivasi dan membuat siswa untuk melalui prosedur permainan secara teliti untuk mengembangkan kemampuan mereka.

\section{B. Sungai Kapuas}

Sungai Kapuas merupakan sungai yang ada di Kalimantan Barat. Merupakan sungai terpanjang di Indonesia dengan panjang $1086 \mathrm{~km}$. Sebagai sarana transportasi antar daerah, sumber air baku dan tempat wisata. Sungai Kapuas telah tercemar logam berat, berbagai jenis bahan kimia serta sampah yang ada di badan sungai. Walaupun telah tercemar, Sungai Kapuas tetap menjadi urat nadi bagi kehidupan masyarakat bantaran sungai.

\section{Android}

Android merupakan sistem operasi yang memakai basis kode komputer yang dapat didistribusikan secara terbuka atau open source sehingga pengguna bisa membuat aplikasi baru di dalamnya[6]. Pengembangan aplikasi android dipermudah dengan banyaknya tools yang disediakan untuk mengembangkan aplikasi dengan platform ini.

\section{Construct 2}

Construct 2 adalah sebuah program untuk membuat permainan komputer HTML5, hanya dengan menggunakan lingkungan pengembangan "drag and drop" yang intuitif [7]. Program bisa digunakan tanpa harus menulis kode yang rumit. Construct 2 memiliki unsur-unsur seperti sprite, latar belakang, dan efek suara.

\section{PERANCANGAN APLIKASI}

\section{A. Perancangan UML}

\section{Use Case Diagram}

Use Case Diagram menggambarkan fungsionalitas yang diharapkan dari sebuah sistem[8]. Sebuah use case mereprensentasikan interaksi antara aktor dengan system. Berikut merupakan use case diagram yang telah dirancang pada gambar berikut.

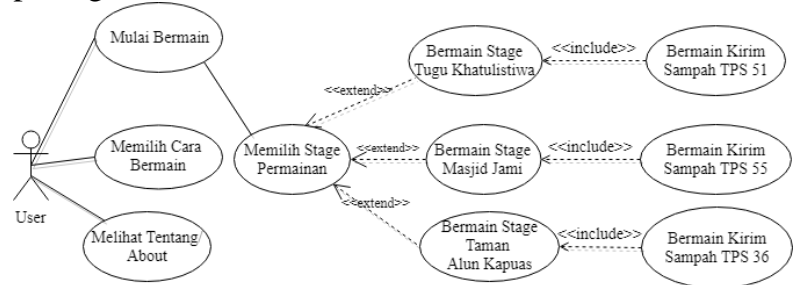

Gambar 1 Use Case Diagram

Pengguna atau user dapat memilih menu mulai bermain, Cara Bermain, About, Stage Permainan yang terdiri dari stage Tugu Khatulistiwa, Stage Masjid Jami dan Stage Taman Alun Kapuas.

\section{Activity Diagram}

Activity Diagram menggambarkan alir aktivitas sistem yang sedang dirancang, bagaimana alir berawal, decision yang mungkin terjadi dan bagaimana alir berakhir [9]. Berikut merupakan gambar activity diagram yang telah dirancang pada gambar berikut.

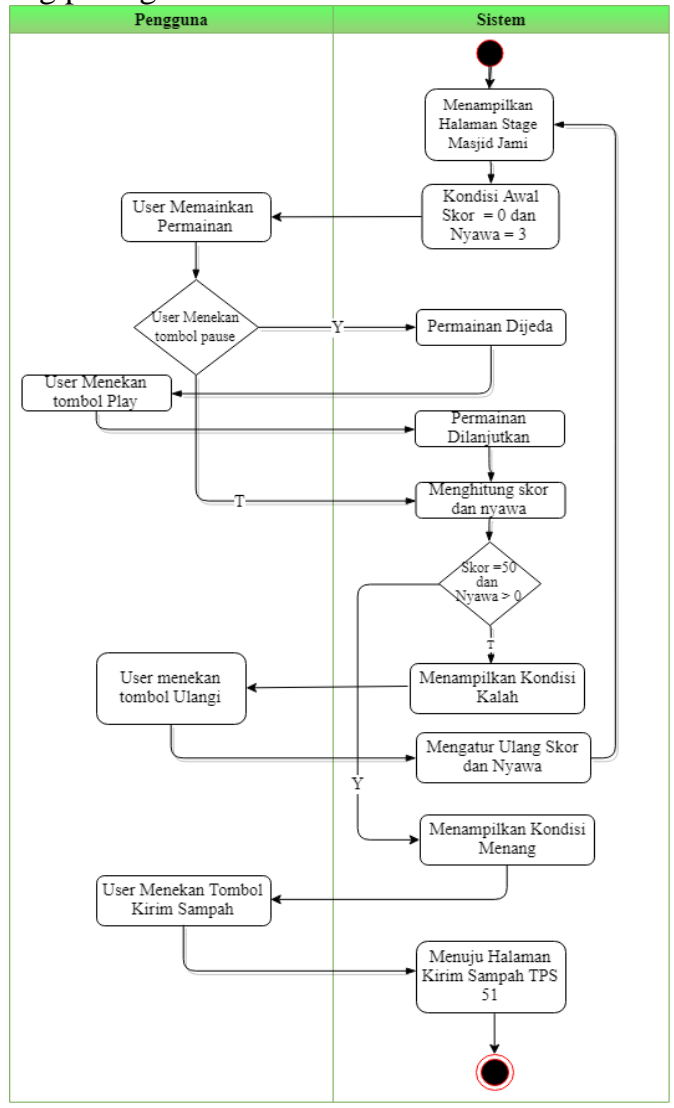

Gambar 2 Activity Diagram

\section{Class Diagram}

Class Diagram menggambarkan menggambarkan struktur sistem dari segi pendefinisian kelas-kelas yang akan dibuat untuk membangun sistem [10]. Berikut merupakan gambar class diagram yang telah dirancang pada gambar berikut. 


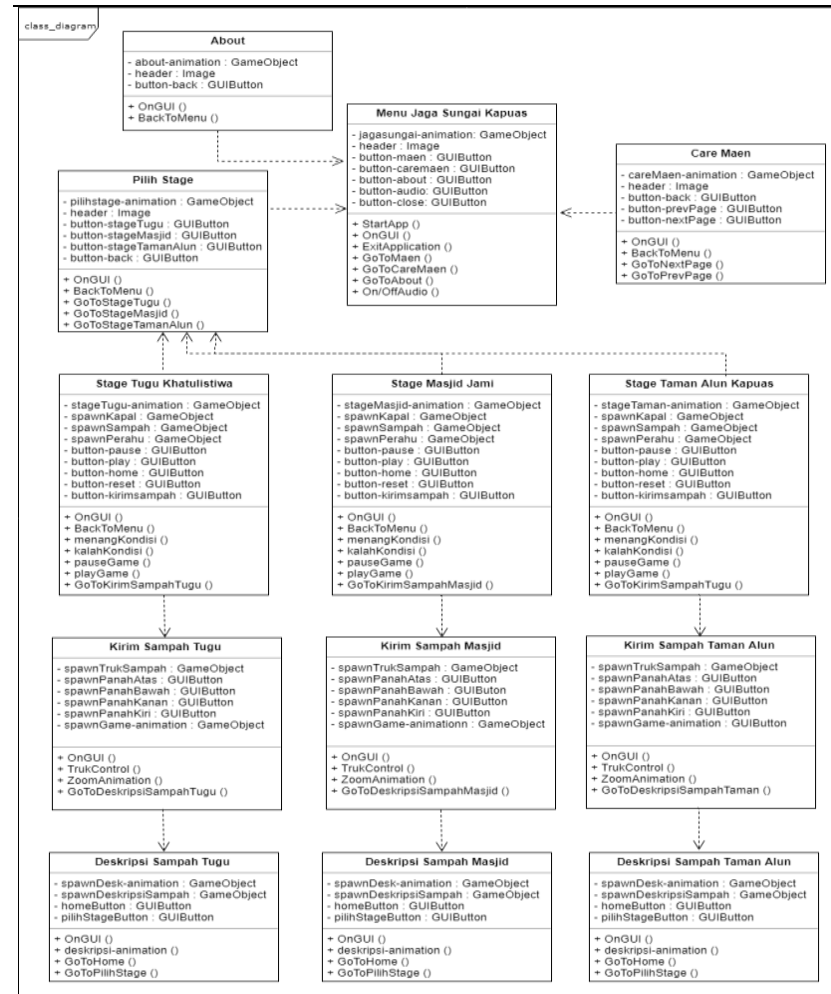

Gambar 3 Class Diagram

Berdasarkan gambar, terdapat class Menu yang dapat menampilkan class menu Bermain, yang dapat menampilkan class stage_perrmainanController, carabermainController, dan class tentangController.

\section{B. Perancangan Antarmuka}

Aplikasi game Jaga Sungai Kapuas ini memiliki beberapa layout yang disesuaikan dengan use case diagram yang telah dirancang. Pada game ini terdiri dari menu utama, menu mulai bermain, cara bermain, about dan keluar. Struktur antar muka game yang dibangun dapat dilihat pada gambar 4 berikut :

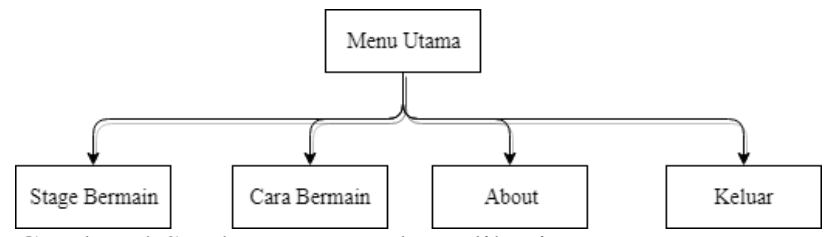

Gambar 4 Struktur antarmuka aplikasi

\section{HASIL PERANCANGAN DAN ANALISIS}

\section{A. Antarmuka тепи utama}

Antarmuka menu dari hasil perancangan aplikasi game Jaga Sungai Kapuas ini dapat dilihat pada gambar .

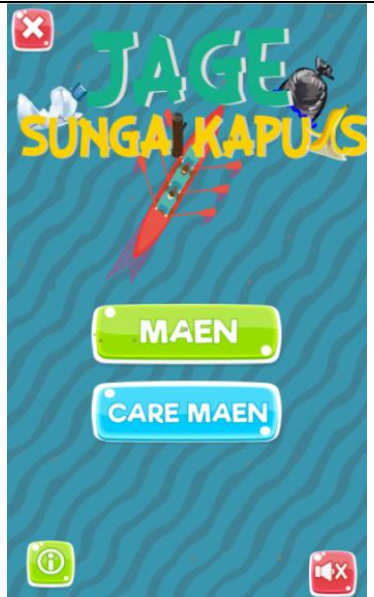

Gambar 5 Menu Utama Jaga Sungai Kapuas

Menu Utama yang terdiri dari Menu Bermain yang ketika dipilih akan mengarahkan ke Menu Pilih Stage, Cara Bermain, dan About (i).

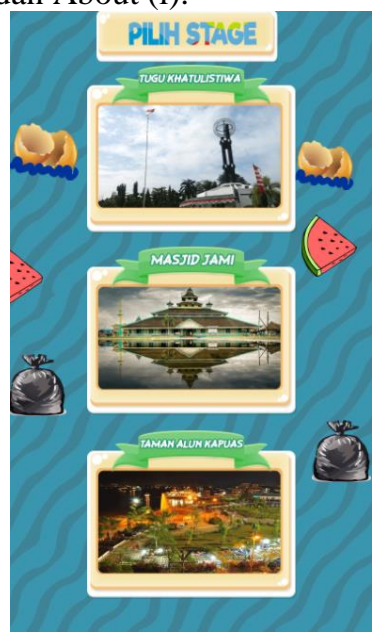

Gambar 6 Stage Permainan

Menu Stage Bermain yang terdiri dari Stage Tugu, Stage Masjid Jami dan Stage Taman Alun.

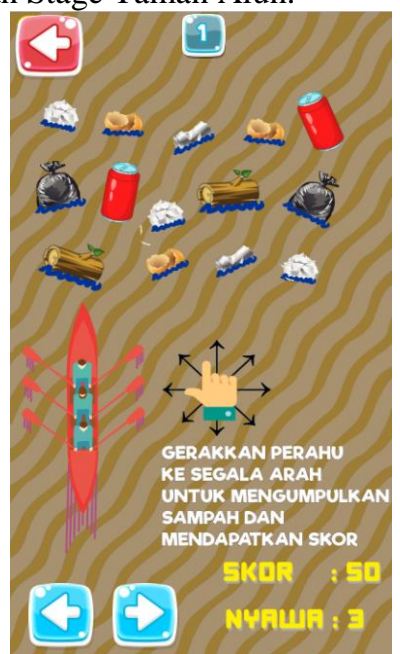

Gambar 7 Cara Bermain

Menu Cara Bermain yang menjelaskan cara bermain,arah panah dapat ditekan untuk menavigasi ke halaman berikutnya pada Cara Bermain. 


\section{B. Pengujian Alpha}

Pengujian alpha digunakan untuk menguji sistem yang dibuat dan berfokus pada persyaratan fungsional perangkat lunak. Pengujian ini dilakukan untuk mengoreksi kesalahan-kesalahan dan kekurangan pada aplikasi.

\begin{tabular}{|c|c|c|c|}
\hline \multirow{2}{*}{ No. } & \multirow{2}{*}{ Pernyataan } & \multicolumn{2}{|c|}{ Ahli } \\
\hline & & 1 & 2 \\
\hline \multicolumn{4}{|c|}{ Variabel Functionality } \\
\hline 1. & $\begin{array}{l}\text { Game menampilkan } 3 \text { jenis stage } \\
\text { permainan }\end{array}$ & 3 & 4 \\
\hline 2. & $\begin{array}{l}\text { Game menampilkan gameplay } \\
\text { mengumpulkan sampah. }\end{array}$ & 4 & 4 \\
\hline 3. & $\begin{array}{l}\text { Game menampilkan gameplay } \\
\text { mengantar sampah ke TPS. }\end{array}$ & 4 & 4 \\
\hline 4. & $\begin{array}{l}\text { Game menampilkan deskripsi masing- } \\
\text { masing sampah. }\end{array}$ & 3 & 4 \\
\hline 5. & Game menampilkan Cara bermain & 4 & 4 \\
\hline 6. & $\begin{array}{l}\text { Game menampilkan skor di setiap } \\
\text { stage. }\end{array}$ & 4 & 4 \\
\hline 7. & Fitur sesuai fungsinya masing-masing. & 4 & 4 \\
\hline \multicolumn{4}{|c|}{ Variabel efficiency } \\
\hline 8. & Proses pada fitur singkat. & 4 & 4 \\
\hline 9. & Respon sesuai dengan fungsinya. & 3 & 4 \\
\hline \multicolumn{4}{|c|}{ Variabel Usability } \\
\hline 10. & Menu jelas & 4 & 4 \\
\hline 11. & Informasi mudah dipahami. & 3 & 4 \\
\hline 12. & Menu mudah dipelajari & 2 & 4 \\
\hline 13. & $\begin{array}{l}\text { Permainan mudah } \\
\text { dipelajari/dimainkan }\end{array}$ & 5 & 4 \\
\hline 14. & $\begin{array}{l}\text { Menu/fitur menggunakan objek } \\
\text { yang menarik }\end{array}$ & 4 & 4 \\
\hline 15. & Kelengkapan menu operasi & 2 & 4 \\
\hline 16. & Menu yang ada menarik & 3 & 4 \\
\hline
\end{tabular}

Tabel 1 Data pengujian alpha

Penguji ahli perangkat lunak yang juga memberikan saran dan rekomendasi untuk memperbaiki bug dan kekurangan pada aplikasi. Bagian-bagian aplikasi yang perlu diperbaiki dijelaskan pada Tabel 4.18.

\begin{tabular}{|c|l|}
\hline No. & Saran \\
\hline 1. & $\begin{array}{l}\text { Perlu ditambahkan petunjuk proses } \\
\text { membawa sampah ke TPS terdekat }\end{array}$ \\
\hline 2. & $\begin{array}{l}\text { Setiap stage harus diberikan rintangan } \\
\text { yang berbeda agar user lebih tertantang }\end{array}$ \\
\hline 3. & $\begin{array}{l}\text { Disisipkan tampilan yang berisi slogan } \\
\text { untuk menjaga kebersihan sungai }\end{array}$ \\
\hline 4. & Halaman Cara Bermain harus berisi \\
\hline
\end{tabular}

\begin{tabular}{|c|l|}
\hline & $\begin{array}{l}\text { instruksi yang lebih lengkap agar } \\
\text { memudahkan user }\end{array}$ \\
\hline 5. & $\begin{array}{l}\text { Melengkapi menu operasi, menambahkan } \\
\text { halaman loading yang berisi petunjuk di } \\
\text { setiap gameplay }\end{array}$ \\
\hline 6. & $\begin{array}{l}\text { Respon setiap menu harus diperbaiki, } \\
\text { audio harus berjalan tanpa ada jeda. }\end{array}$ \\
\hline
\end{tabular}

Tabel 2 Saran pengujian alpha

\section{Pengujian Beta}

Pengujian Beta dilakukan untuk mendapatkan usulan dari pengguna akhir sebelum persiapan rilis produk akhir. Pengujian ini dilakukan dengan melibatkan 20 pengguna aplikasi yang telah ditentukan sebelumnya. Pengguna aplikasi tersebut akan menguji perangkat lunak untuk mengetahui kualitas perangkat lunak pada aspek Functionality, Efficiency, Usability dan Portability. Hasil pengujian beta dapat dilihat dari tabel berikut.

\begin{tabular}{|c|c|c|c|c|}
\hline Variabel & $\begin{array}{c}\text { Functio } \\
\text { nality }\end{array}$ & $\begin{array}{c}\text { Efficien } \\
\text { cy }\end{array}$ & Usability & $\begin{array}{c}\text { Portabil } \\
\text { ity }\end{array}$ \\
\hline $\begin{array}{c}\text { Total Skor } \\
\text { (20 user) }\end{array}$ & 648 & 170 & 613 & 179 \\
\hline $\begin{array}{c}\text { Skor } \\
\text { Maksimum }\end{array}$ & 700 & 200 & 700 & 200 \\
\hline Rerata Item & 4,60 & 4,25 & 4,38 & 4,48 \\
\hline Persentase & $93 \%$ & $85 \%$ & $88 \%$ & $89 \%$ \\
\hline
\end{tabular}

Tabel 3 Data hasil pengujian Beta

Dari hasil pengujian didapatkan bahwa aplikasi game Jaga Sungai Kapuas mendapatkan nilai fungsionalitas sebesar 93\%, Efficiency $85 \%$, Usability $88 \%$ dan Portability $89 \%$. Kemudian hasil evaluasi dibandingkan persetanse Likert.

Tabel Interpretasi Persentase Likert untuk Kualitas Perangkat Lunak

\begin{tabular}{|c|l|l|}
\hline No. & Persentase & Interpretasi \\
\hline 1. & $0 \%-20 \%$ & Sangat Tidak Layak \\
\hline 2. & $21 \%-40 \%$ & Tidak Layak \\
\hline 3. & $41 \%-60 \%$ & Cukup Layak \\
\hline 4. & $61 \%-80 \%$ & Layak \\
\hline 5. & $81 \%-100 \%$ & Sangat Layak \\
\hline
\end{tabular}

Tabel 4 Skala interpretasi likert

Perhitungan persentase kualitas perangkat lunak secara keseluruhan dari data hasil pengujian Beta menggunakan rumus:

Persentase Kelayakan $(\%)=$ $\frac{\text { Skor yang diobservasi }}{\text { Skor yang diharapkan }} \times 100 \%$
Persentase Kelayakan $(\%)=\frac{1610}{1800} \times 100 \%$
Persentase Kelayakan $(\%)=89,44 \%$ 


\section{Analisis Hasil Pengujian}

Berdasarkan hasil pengujian Alpha, perangkat lunak telah memiliki bahwa menu-menu yang terdapat dalam aplikasi sudah memiliki fungsi yang sesuai dengan analisis kebutuhan yang telah ditetapkan sebelumnya. Namun, terdapat beberapa kekurangan seperti kurang lengkapnya menu operasi dan tampilan per menu/fitur yang kurang mudah untuk dipelajari. Sehingga perlu diadakan beberapa perbaikan sektoral sesuai dengan pendapat penguji Ahli.

Setelah melalui revisi pengujian Alpha, berdasarkan dari hasil pengujian Beta pada 20 orang pengguna awam, aplikasi "Game Jaga Sungai Kapuas" mendapatkan persentase yang cukup tinggi untuk dari aspek Functionality, Efficiency, Usability dan Portability dengan persentase kelayakan sebesar $89,44 \%$. Dari hasil pengujian ini, dapat disimpulkan bahwa revisi pada pengujian Alpha di bagian menu dan fitur aplikasi telah berhasil. Sehingga pengguna awam pada pengujian Beta bisa memahami setiap fitur/menu dan mendapatkan kelengkapan menu operasi serta instruksi pada setiap stage dapat dengan mudah dipahami.

\section{KESIMPULAN DAN SARAN}

A. Kesimpulan

1. Aplikasi Game Jaga Sungai Kapuas telah mampu mengedukasi masyarakat tentang jenis-jenis sampah dan persebaran lokasi TPS terdekat dari sungai Kapuas.

2. Hasil unjuk kerja aplikasi "Game Jaga Sungai Kapuas" masuk dalam kategori "Sangat Layak". Hasil pengujian unjuk kerja ini didukung oleh hasil pengujian Alpha dan Beta perangkat lunak. Nilai persentase hasil pengujian Alpha perangkat lunak untuk setiap faktor, yaitu: Functionality sebesar $77,00 \%$, Efficiency sebesar 75,00\%, dan Usability sebesar $73 \% \%$. Persentase total dari pengujian alpha untuk kualitas perangkat lunak adalah 75\% (Layak). Nilai persentase hasil pengujian Beta perangkat lunak untuk setiap faktor, yaitu Functionality sebesar 93\%, Efficiency sebesar $85 \%$, Usability sebesar $88 \%$, dan Portability sebesar $89 \%$. Persentase total dari pengujian Beta untuk kualitas dari pengujian Beta adalah $89,44 \%$ (Sangat Layak).

B. Saran

Hal-hal yang menjadi saran dalam pengembangan aplikasi ini adalah:

1. Pengembangan aplikasi untuk jumlah stage permainan dan jenis permainan yang lebih menantang dan beragam.

2. Penambahan referensi pada materi yang disajikan sehingga menjadi lebih lengkap.

3. Aplikasi juga dapat digunakan untuk perangkat yang menggunakan sistem operasi iOS.

\section{DAFTAR PUSTAKA}

[1] Nia, Febrianti, Studi Beban Pencemaran Sungai Kapuas Akibat Buangan dari Drainase di Kecamatan Pontianak Utara Kota Pontianak, Indonesia: Jurnal Teknik Lingkungan, Vol. 1, No. 1, 2014

[2] U. Kadaria dan D.R. Jati, Pengaruh Aspek Pengetahuan dan Pendidikan Masyarakat Tepi Sungai Kapuas dalam Membuang Sampah, Indonesia: Jurnal Vokasi Kesehatan, Vol.4, No. 1, 2018.

[3] (2017) JUSTIN (Jurnal Sistem dan Teknologi Informasi) website [Online]. Available

http://jurnal.untan.ac.id/index.php/jepin/article/ view/16354/14204

[4] Wena, Made. 2011. Strategi Pembelajaran Inovatif Kontemporer Suatu Tinjauan Konseptual Operasional. Jakarta. Bumi Aksara.

[5] Handriyantini, Eva \& Kom, S \& Mt, M. 2009. Permainan Edukatif (Educational Games) Berbasis Komputer untuk Siswa Sekolah Dasar. Bandung: Konferensi dan Temu Nasional Teknologi Informasi dan Komunikasi untuk Indonesia.

[6] Safaat, Nazruddin. 2012. Pemrograman Aplikasi Mobile Smartphone dan Tablet PC Berbasis Android. Bandung: Edisi Revisi. Informatika.

[7] Gullen, Ashley dan Thomas Gullen. 2011. Construct 2. http://www.scirra.com/construct 2, ( diakses tanggal 15 Agustus 2017).

[8] (2017) JEPIN (Jurnal Edukasi dan Penelitian Informatika) website [Online]. Available http://jurnal.untan.ac.id/index.php/jepin/article/ view/22676

[9] Pressman, R.S. 2010. Rekayasa Perangkat Lunak: Pendekatan Praktisi. Yogyakarta: Andi.

[10] A.S., Rosa dan M. Shalahudin. 2016. Rekayasa Perangkat Lunak Terstruktur dan Berorientasi Objek. Bandung: Informatika Bandung. 